Running head: WORKING MEMORY AND READING DISABILITIES

\title{
Working Memory in Children with Reading Disabilities
}

\author{
Susan Elizabeth Gathercole $\quad$ Tracy Packiam Alloway \\ University of Durham
}

Catherine Willis Anne-Marie Adams

Liverpool John Moores University

Address for correspondence:

Professor Susan E. Gathercole

Department of Psychology

University of Durham

Science Laboratories

South Road

Durham DH1 3LE

Email: s.e.gathercole@durham.ac.uk

Tel: 01913343255

Fax: 01913343241 
This study investigated associations between working memory and both reading and mathematics abilities, and the possible mediating factors of fluid intelligence, verbal abilities, short-term memory and phonological processing skills, in a sample of 46 children aged between 6 and 11 years with reading disabilities. Participants were tested on measures of complex memory, verbal and visuospatial short-term memory, IQ, phonological processing, language, literacy and mathematics. As a whole, the sample was characterized by deficits in complex memory and visuospatial short-term memory and by low IQ scores, whereas language, phonological short-term memory and phonological processing abilities fell in the low average range. The severity of reading difficulties was significantly associated with working memory, language and phonological processing abilities, whereas poor mathematics abilities were associated with complex memory score, phonological short-term memory and phonological processing scores. These findings suggest that working memory skills indexed by complex memory represent an important constraint on the development of skill and knowledge in the key domains of reading and mathematics. Possible mechanisms for the contribution of working memory to learning and the implications for educational practice are considered.

Key words: (up to 5)

Reading disabilities

Working memory

Short-term memory

IQ

Mathematics 


\section{Working Memory in Children with Reading Disabilities}

The purpose of this study was to investigate the extent to which impairments of working memory contribute to the severity of the learning difficulties experienced by children with reading disabilities. Although close links between memory function and individual variation in a range of aspects of learning and academic achievement in unselected samples of children are well established, the degree to which working memory deficits specifically constrain learning progress within children with recognized learning disabilities is less well understood. The study focuses in particular on the extent to which impairments of working memory contribute to the problems in both reading and mathematics commonly experienced by children with learning disabilities, and on whether any associations that are found could be mediated by other aspects of cognitive function.

Immediate memory comprises several related sub-systems of memory. The capacity to store material over short periods of time in situations that do not impose other competing cognitive demands is typically referred to as short-term memory. Findings from experimental, developmental, and neuropsychological studies indicate that short-term memory is fractionated into at least two domain-specific components that are specialized for the retention of phonological and visuospatial material (see Gathercole, 1999, and Vallar \& Papagno, 2002, for reviews). In terms of the influential working memory model of Baddeley and Hitch (1974), developed subsequently by Baddeley (1986, 2000), these components correspond to two slave systems: the phonological loop retains material in a phonological code that is highly susceptible to time-based decay, and the visuospatial sketchpad has limited capacities to represent information in terms of its visual and spatial characteristics. The phonological loop is assessed using methods such as the recall of digit or word sequences, and visuo-spatial sketchpad functioning is typically measured by tasks involving the recall or recognition of visual patterns or sequences of movement. 
Working memory is related to but distinguishable from short-term memory. The term is widely used to refer to the capacity to store information while engaging in other cognitively demanding activities, and is most commonly assessed using complex memory paradigms that impose demands both for temporary storage and significant processing activity with selected task components varied across domains. An example of a complex memory task is listening span, in which the participant is asked to make a meaning-based judgment about each of a series of spoken sentences, and then remember the last word of each sentence in sequence (e.g., Daneman \& Carpenter, 1980). Another task is counting span, which involves participants in counting target items in successive arrays, and then recalling in sequence the tallies of the arrays (Case, Kurland, \& Goldberg, 1982). Despite disparate processing demands, scores on the two tasks are highly correlated (e.g., Gathercole, Pickering, Ambridge, \& Wearing, 2004) and are linked also with performance on memory updating tasks that are also believed to tap working memory (Jarvis \& Gathercole, in press; Miyake, Friedman, Emerson, Witzki, Howerter, \& Wager, 2000).

Most theoretical accounts of immediate memory incorporate a distinction between the storage-only capacities of short-term memory and the broader and more flexible nature of working memory. In addition to the domain-specific storage systems of the phonological loop and the visuospatial sketchpad, the Baddeley and Hitch model (1974) includes the central executive, responsible for a range of functions including the retrieval of information from long-term memory, the regulation of information within working memory, the attentional control of both encoding and retrieval strategies, and task shifting (Baddeley, 1986, 1996). Proponents of the working memory model have suggested that the storage demands of complex memory tasks depend on appropriate subsystems, with processing demands supported principally by the central executive (Baddeley \& Logie, 1999; Cocchini, Logie Della Sala, MacPherson, \& Baddeley, 2002). Thus complex memory span such as listening 
and counting span appear to tap both the central executive and the phonological loop (Lobley, Gathercole, \& Baddeley, in press), whereas analogous visuospatial complex memory tasks (Jarvis \& Gathercole, 2003; Shah \& Miyake, 1996) may draw upon the resources of the central executive and the visuospatial sketchpad. There is a substantial domain-general component to such working memory tasks (e.g., Bayliss, Jarrold, Gunn, \& Baddeley, 2003; Kane, Hambrick, Tuholski, Wilhelm, Payne, \& Engle, 2004; Swanson \& Sachse-Lee, 2001) that has been interpreted as reflecting central executive function.

Another influential conceptualization of working memory is of a limited resource that can be flexibly allocated to support either processing or storage (e.g., Daneman \& Carpenter, 1980; Just \& Carpenter, 1992). According to one model in this theoretical tradition, developmental increases in complex memory performance reflect improvements in processing speed and efficiency that release additional resources to support storage (Case et al., 1982). Other theorists have proposed that working memory consists of activated longterm memory representations, and that short-term memory is the subset of working memory that falls within the focus of attention (Cowan, 2001; Engle, Kane, \& Tuholski, 1999).

As the present research is not concerned specifically with distinctions between models, the theoretically neutral terms phonological and visuospatial short-term memory will be used to refer to storage-only assessments of the respective informational domains, and complex memory tasks will be interpreted as tapping working memory. The primary focus is on the extent which working memory is associated with the scholastic abilities of with reading disabilities, characterized by marked difficulties in mastering skills including word recognition, spelling, and reading comprehension. Working memory is already known to be linked with reading ability. In typically developing samples of children, scores on complex memory tasks predict reading achievement independently of measures of phonological shortterm memory (e.g., Swanson, 2003; Swanson \& Howell, 2001). Current evidence suggests 
that although phonological short-term memory is significantly associated with reading achievements over the early years of reading instruction, its role is as part of a general phonological processing construct related to reading development rather than representing a causal factor per se (Wagner et al., 1997; Wagner \& Muse, in press). It is also well established that children with reading disabilities show significant and marked decrements on working memory tasks relative to typically developing individuals (Siegel \& Ryan, 1989; Swanson, 1994, 1999; Swanson, Ashbaker, \& Lee, 1996).

Mathematical difficulties commonly accompany reading disabilities (Swanson \& Saez, 2003), and are also characterized by deficits in working memory. Associations between working memory and mathematical ability vary across age and level of expertise, probably due to the changes in procedures and strategies that characterise mathematical development. For example, addition commences with simple counting strategies, success at which contributes to the gradual acquisition of arithmetic facts. More complex addition computations require memory-based problem solving involving either the direct retrieval of facts or problem decomposition, leading to eventual automatic retrieval of facts (Geary 2004). Working memory appears to play an important role at the earliest stage of counting: children with low scores on complex memory tasks are more likely to use primitive fingerbased counting strategies than those with high scores, possibly due to the relatively low working memory demands of the activities (Geary, Hoard, Byrd, Craven, \& DeSoto, 2004). In addition, low working memory scores have been found to be strongly and specifically associated both with poor computational skills (Wilson \& Swanson, 2001) and difficulties in solving mathematical problems expressed in everyday language (Swanson \& Sachse-Lee, 2001).

A key question is how deficits of working memory contribute to impairments of learning in reading and mathematics. One explanation is that impairments of working memory 
compromise the crucial process, for both mathematics and reading, of maintaining recently retrieved knowledge and integrating this with recent inputs (Swanson \& BeebeFrankenberger, 2004). A related suggestion is that learning activities in literacy and mathematics classes often impose heavy demands on working memory, resulting in frequent task failures in children with poor working memory function. As a result, the normal incremental process of acquiring knowledge and skills in these domains is impaired (Gathercole, 2004). In a more specific account of the association between working memory and mathematical abilities, Geary et al. (2004) proposed that poor working memory capacity impairs the process of acquiring mathematical facts that arises from successful counting strategies.

The participants in the present study were children identified by their schools as having reading difficulties of sufficient severity to warrant remedial support and who scored at least $1 S D$ below the mean on a standardized measure of reading ability that included subtests of word recognition, spelling, and reading comprehension (Wechsler, 1993). These criteria were less restrictive than the majority of studies in this field, which typically include only children who perform within the normal range on tests of fluid intelligence (e.g., Siegel \& Ryan, 1989; Swanson \& Sachse-Lee, 2001), as reflected in nonverbal reasoning measures such as Coloured Progressive Matrices (Raven, 1986) or performance IQ from the Wechsler Intelligence Scales for Children - III Revised $^{\mathrm{UK}}$ (Wechsler, 1992). An issue raised by close associations between working memory and fluid intelligence (e.g., Conway, Kane, \& Engle, 2003; Engle, Tuholski, Laughlin, \& Conway, 1999; Fry \& Hale, 2000) is whether variation in fluid intelligence abilities underpins links between working memory and achievements in reading and mathematics. Although working memory deficits in children with learning difficulties have been found to persist even after fluid intelligence has been taken into account (Swanson \& Sachse-Lee, 2001), the inclusion in such studies only of children with 
intelligence scores in the normal range limits sensitivity to this potentially confounding factor. Selecting children purely on the basis of their reading disabilities without restricting the range of intelligence scores leads to a much stronger test of whether links between complex memory scores and learning achievements reflect differences in fluid intelligence rather than a specific working memory construct.

Three further potential mediating factors relating to aspects of verbal ability were also investigated. First, several researchers have argued that the key factor underlying individual differences on working memory tests is general verbal ability (Nation, Adams, BowyerCrane, \& Snowling, 1999; Stothard \& Hulme, 1992). Although there is already some evidence that working memory skills are dissociable from verbal ability more generally (Cain, Oakhill, \& Bryant, 2004; Siegel, 1988), it was important to test whether the two factors could be distinguished in the present wide-ranging set of children with learning difficulties. If working memory performance is simply a proxy for general ability, potential associations between working memory and abilities in mathematics and literacy should be eliminated measures of verbal ability such as language and verbal IQ are taken into account.

A further potential factor underlying the working memory measures is phonological short-term memory. Scores on short-term memory and complex memory tests are moderately associated with one another (e.g., Gathercole \& Pickering, 2000; Gathercole et al., 2004), probably due to the role played by phonological STM in supporting the storage component of the complex memory measures (Baddeley \& Logie, 1999; Lobley et al., in press). The extent to which short-term memory and complex span measures are independently associated with learning achievements in this sample will establish whether possible associations are mediated by the contribution of STM abilities rather than working memory more generally, The final mediating factor we considered was phonological processing. Phonological processing skills as tapped by tasks requiring the manipulation of phonological structure are 
highly associated with both reading ability (e.g., Bradley \& Bryant, 1985; Brady \& Shankweiler, 1991; Catts, Gillispie, Leonard, Kail, \& Miller, 2002; Stanovich \& Siegel, 1994; Wagner \& Torgesen, 1987; Wolf \& Bowers, 1999) and mathematical skills (e.g., Geary, Hoard, \& Hamson, 1999; Rourke \& Conway, 1997). It has been argued that both phonological processing and STM measures reflect a common phonological processing substrate (Bowey, 1996; Metsala, 1999). On the basis of the significant verbal storage component of working memory tasks, this account could also be extended to encompass verbal working memory. In order to test whether possible associations between working memory and learning abilities are mediated by phonological processing skills more generally, standardized assessments of phonological processing abilities (Fredrickson, Reason, \& Frith, 1997) were also included in the present study.

A further prediction tested in this study was that working memory should constrain both reading and mathematics abilities to a common extent. In a recent study of working memory in children with learning disabilities (Pickering \& Gathercole, 2004), we found that children classified by their schools as having problems in both reading and mathematics had depressed performance on complex memory tasks, but that individuals with difficulties restricted to reading did not. Thus, working memory deficits appeared to have been associated with more pervasive learning disabilities that extended beyond reading alone. It was therefore predicted that associations between complex memory measures and reading would be abolished when differences in mathematical abilities were taken into account, and vice versa.

\section{Method}

\section{Participants}

Data are reported for 46 children (13 girls, 33 boys) with a mean age of 9.00 years (range 6.06 to 11.00 years, $S D=12$ months) taken from a larger study of children identifying by their schools as having special educational needs that required additional educational 
support. All children were attending state schools in the Durham area of North-East England. None of the children had emotional or behavioral difficulties, and each child obtained a composite standard score of less than 86 on the Wechsler Objective Reading Dimension (WORD, Wechsler, 1993). This score is derived from three subtests: reading (of letters and single words), spelling (of letters and single words), and reading comprehension (involving passage reading followed by orally presented questions). Test-retest reliability coefficients for children aged between 6 and 11 years range from .94 to .96 for reading, from .90 to .96 for spelling, and from .90 to .94 for reading comprehension in the WORD.

All children were also tested on a measure of mathematical skills, the Wechsler Objective Numerical Dimensions (WOND, Wechsler, 1996a). This includes two subtests, mathematical reasoning and numerical operations. The mathematical reasoning subtest is designed to tap the ability to reason mathematically, and incorporates a wide range of materials requiring skills such as shape identification, telling the time, solving mathematical problems expressed in language, and interpretation of graphs and charts. The numerical operations subtest measures abilities to solve computational problems involving mathematical operations such as addition, subtraction, multiplication, division, and algebra. Test-retest reliability coefficients for children aged between 6 and 11 years range from .85 to .92 for mathematical reasoning, from .82 to .91 for numerical operations, and from .90 to .95 for the composite in the WOND. Descriptive statistics for the reading and mathematics measures are shown in Table 1. Scores on the WORD were low across all three subtests (reading, spelling, and comprehension), with a sample mean composite score of 76.46. Scored on the WOND were higher overall (composite score mean=84.39), with lower performance on the number operations than the mathematical reasoning subtest.

Table 1 about here 


\section{Procedure}

Each child was tested individually in a quiet area of the school for six sessions lasting up to 30 minutes per session across six weeks. The following tests were administered by a member of the research team (TPA) in a fixed sequence designed to vary task demands across the testing session.

Ability tests. All participants were administered the Wechsler Objective Language Dimensions (WOLD; Wechsler, 1996b). This test battery assesses receptive and expressive aspects of oral language function in two subtests: listening comprehension, and oral expression. The listening comprehension subtest taps understanding of orally presented words and passages, with performance measured either by picture pointing or oral responses. The oral expression subtest assesses abilities to express a target word that has been defined and to orally describe scenes, give directions, and explain steps. Test-retest reliability coefficients for children aged between 6 and 11 years range from .83 to .88 for listening comprehension, .90 to .92 for oral expression, and from .91 to .93 for the composite test score. Participants also completed the Wechsler Intelligence Scale for Children - 3rd UK Edition (WISC-III ${ }^{\mathrm{UK}}$; Wechsler, 1992), yielding measures of verbal IQ and performance IQ. Test-retest reliability coefficients range from .92 to .96 for verbal IQ, and from .90 to .91 for performance IQ.

Memory tests. Three verbal complex memory measures from the Working Memory Test Battery for Children (WMTB-C, Pickering \& Gathercole, 2001) were administered: backwards digit recall, counting recall, and listening recall. In backwards digit recall, the child is required to recall a sequence of spoken digits in the reverse order. The number of digits in each list increases across trials, and the number of lists correctly recalled is scored. In counting recall, the child is required to count the number of dots in an array, and then 
recall the tallies of dots in the arrays in the sequence in which they were presented. The number of dots in the array increases across trials, and the number of correct trials completed by each child is scored. In listening recall, the child listens to a series of short sentences, determines the veracity of the statements by responding 'true' or 'false', and recalls the final word of each sentence in sequence. The number of sentences in each block increases across trials, and the number of correct trials is scored. Test-retest reliability coefficients for children aged between 5 and 8 years are .53, .74, and .83 for backward digit recall, counting recall and listening recall respectively. For children ages between 9.5 years and 11.5 years, test-retest reliability for backward digit recall, counting recall and listening recall are .71, .48, and .38 respectively.

Three measures of phonological short-term memory from the WMTB-C (Pickering \& Gathercole, 2001) were administered. Digit recall and word list recall both involve spoken recall of sequences of spoken items (either single digits or high frequency monosyllabic words). In each case, the number of items in each sequences increases across trials, and the number of correct trials is scored. Word list matching involves the child detecting whether words in a second list are in the same order as in the first word list. The number of lists increases in each block, and the number of correct trials is scored. Test-retest reliability coefficients for children aged between 5 and 8 years are .81, .80, and .45 for digit recall, word list recall and word list matching respectively. For children ages between 9.5 years and 11.5 years, test-retest reliability for digit recall, word list recall and word list matching are .82, .64, and .42 respectively.

Two measures of the visuo-spatial component were administered. In the block recall test of the WMTB-C (Pickering \& Gathercole, 2001), a child views nine cubes randomly located on a board. The test administrator taps a sequence of blocks, and the child has to tap that sequence in the correct order. The number of correct trials is recorded. Test-retest 
reliability coefficients are .63 and .43 for children aged between 5 and 8 years, and between 9.5 years and 11.5 years, respectively. In the Visual Patterns Test (Della Sala, Gray, Baddeley, \& Wilson, 1997), the child views a two-dimensional grid of black and white squares. After viewing the grid for 3 seconds, the child has to mark the black squares on an empty grid. The number of correctly marked grids is scored. This test is standardized for use with children as part of the WMTB-C. No estimates of reliability are available for this measure.

Phonological processing tests. Three measures from the Phonological Assessment Battery (Fredrickson et al., 1997) were administered. The rhyme task assesses the child’s ability to identify rhyming words in sequences of three monosyllabic words such as sand, hand, cup and bead, wheat, seat. In the spoonerism task, the child is required to segment single syllable words and then exchange initial phonemes to produce new word combinations, for example by combining cot with a $/ g$ / to give got, and by transforming riding boot to biding root. The alliteration task assesses the child's ability to identify which two of three monosyllabic words share the same initial phoneme, as in bike, name, nose and cross, twig, truck. Performance on all tasks was scored as the number of correct trials. Testretest reliability coefficients for children aged between 6 and 8 years are .92 , .95, and .90 for rhyme, spoonerism and alliteration tasks respectively. For children aged between 9 years and 11 years, test-retest reliability for rhyme, spoonerism and alliteration tasks are .91, .93, and .84 respectively

\section{Results}

Table 2 provides descriptive statistics for the test scores. Consider first the memory assessments. Very low performance was found on both complex memory and visuospatial short-term memory measures. Phonological short-term memory scores, on the other hand, fell within the low average range. Performance levels were generally consistent across the 
different subtests associated with each area of memory function. Phonological processing performance was at a low average level overall, although it should be noted that performance on the alliteration subtest was rather lower than on the rhyme and spoonerisms subtests. Language ability also fell in the low average range, both for the oral expression and language comprehension subtests. Both verbal and performance IQ scores were at a low level across the group as a whole.

Table 2 about here

In order to investigate the extent to which different children performed at low or average levels on these measures, standard scores were banded $(<81,81-85,86-90,91-95$, $>95$ ) and the number of children obtaining scores in each band for each measure was calculated. Table 3 displays the cumulative frequencies derived from these values. These data establish that the majority of children scored in the lowest band on the complex memory and visuospatial short-term memory measures (61\% and 70\%, respectively), with very small proportions performing in the $85+$ range that can be classified as average ( $9 \%$ and $4 \%$, respectively). About half of the sample also obtained performance IQ scores below 86, although comparable low scores were less common in the remaining measures phonological short-term memory, phonological processing, language and verbal IQ.

Table 3 about here

Subsequent analyses focused on interrelations between the cognitive assessments and achievements in reading and mathematics. Correlation coefficients were computed between the principal measures, and the resulting matrix of correlation coefficients is shown in Table 
4. Complex memory performance was significantly associated with all other measures, and was the strongest predictor of mean reading and mathematics scores of the measures included in the study. Although visuospatial short-term memory scores were very low within this sample, they correlated significantly only with complex memory, phonological processing, and performance IQ scores, and not with either reading or mathematics scores. Phonological short-term memory scores were significantly correlated only with complex memory and mathematics scores. Language scores and verbal IQ were highly associated with one another, and both were significantly correlated with reading and mathematics scores. Performance IQ was highly correlated with all measures with the exception of phonological short-term memory. Phonological processing scores were strongly associated with complex memory scores, and also with both IQ measures and both reading and mathematics scores.

Table 4 about here

Given the high degree of intercorrelation between these measures, it was important to establish which factors independently predicted scores on the reading and mathematics measures. Accordingly, two multiple regression analyses were performed with the composite reading score as the dependent variable; the results of this analysis are summarized in Table 5. Model 1 included the five cognitive measures that were significantly correlated with reading performance in the regression equation: verbal IQ, performance IQ, language, phonological processing, and complex memory. Two measures were significant predictors of reading scores: language and complex memory. In Model 2, the composite mathematics measure was also entered into the regression equation in order to establish the extent to which any factors predicting reading also mediated mathematics performance. The independent 
predictors of reading ability in this analysis were mathematics and language scores, but not complex memory scores.

Tables 5 and 6 about here

The predictors of mathematics scores were also explored in a series of multiple regression analyses. Model 1 included all six cognitive measures that were significantly correlated with mathematics scores: verbal IQ, performance IQ, language, phonological processing, complex memory, and phonological short-term memory. None of the variables predicted significant independent proportions of variance in this analysis. In order to test whether the absence of significant links reflected a shared phonological factor tapped by the three measures of phonological processing, complex span, and phonological short-term memory, three further multiple regression analyses, each of which incorporated only two of these three measures in addition to the two IQ scores and the language measure. In Model 2, which incorporated phonological processing and complex memory span measures, the only significant independent predictor of mathematics scores was complex memory. In Model 3, which included the phonological processing and phonological short-term memory measures, phonological processing was a significant predictor, and phonological short-term memory was marginally nonsignificant ( $p=.052)$. Verbal IQ and complex memory were both significant predictors of mathematics ability in Model 4, which incorporated the complex memory and phonological short-term memory measures. It therefore appears that the three phonological measures all shared a substantial amount of variance with mathematics scores but that of the three measures, the complex memory measure was the strongest single predictor.

\section{Discussion}


Working memory skills were significantly related to the severity of learning difficulties in both reading and mathematics in this sample of children with reading disabilities. As a group, the children had low IQ scores, but performed at even lower levels on measures of working memory (complex memory tasks) and of visuospatial short-term memory. Phonological short-term memory, language and phonological processing abilities in this sample were in the low average range. A key finding was that working memory skill independently predicted the children's attainments in reading and to a lesser extent in mathematics, and that the contribution of working memory was common to both ability domains (see also, Pickering \& Gathercole, 2004). Reading ability was also significantly linked with the children’s language and phonological processing abilities.

The association between working memory and reading ability in this sample of children with learning disabilities was not mediated by fluid intelligence, verbal abilities, short-term memory or phonological processing skills. And despite close links between measures of fluid intelligence and working memory in adult samples (Conway et al., 2003; Engle et al., 1999), fluid intelligence shared no independent associations with either reading or mathematics in the present study. This asymmetry of association provides a strong basis for identifying working memory as a specific and significant contributor to reading disabilities. Attainments in mathematics were more generally related to individual differences common to measures of complex span, phonological processing, and phonological short-term memory, suggesting the contribution of phonological abilities to development of this skill domain. Of the three measures, however, complex memory performance was the single strongest predictor of mathematics abilities.

The specificity of associations between working memory and scholastic attainment in this study is consistent with findings from other developmental samples. First, these associations have been found to persist after differences in fluid intelligence have been 
statistically controlled in samples of children with learning difficulties and normal range intelligence (e.g., Swanson \& Sachse-Lee, 2001). Second, differences in working memory ability in both children with reading comprehension problems and with learning difficulties remain after account has been taken of variation in verbal IQ (Cain et al., 2004; Siegel \& Ryan, 1989), indicating that working memory performance is not simply a proxy for verbal ability. Third, working memory and phonological short-term memory have been found to have dissociable links with learning abilities (e.g., Gathercole \& Pickering, 2000; Swanson et al., 2004), suggesting that variation in working memory scores is not mediated simply by the contribution of phonological STM to performance on complex memory tasks (e.g., Baddeley \& Logie, 1999). This conclusion is reinforced by the present finding that phonological STM performance was not markedly impaired in this sample, and is consistent too with other recent evidence that deficits in phonological STM alone are not associated with substantial learning difficulties (Archibald \& Gathercole, 2004; Gathercole, Tiffany, Briscoe, Thorn \& ALSPAC, 2005).

One limitation of the assessment of working memory skill in the present study is the dependence of verbally-based assessment methods only. The reason for this is that at the time of data collection, robust methods for measuring nonverbal aspects of working memory in children were not available. As a consequence, it is not possible to make claims about the degree of domain generality of the working memory skills under assessment here. Nonverbal complex memory tasks that are suitable for use with children as young as five years of age have now been developed, and have been found in large unselected samples of children to share the majority of variance with the verbal methods used here of counting recall, listening recall, and backwards digit recall (Alloway, Gathercole, \& Pickering, 2005), However, research with a sample of children with Specific Language Impairment has established substantial decrements in the verbal complex memory measures but age-appropriate 
performance on the visuospatial complex memory tasks. The extent to which the working memory problems of the present sample are restricted to verbal working memory must therefore remain at present an open issue.

The independence of the working memory association with severity of learning difficulties from phonological processing skills is also consistent with other findings from studies of children with learning difficulties (e.g., Swanson \& Beebe-Frankenberger, 2004). Although the phonological awareness skills of the reading disabled children participating in the present study were relatively low, the deficits were neither as extreme nor as marked as the working memory deficits. In the light of substantial evidence that children with reading difficulties have poor phonological processing, it is perhaps surprising these skills fell within the average range for the majority of children in the sample. This finding may reflect the age range of the group, which included children as old as 11 years; in most typically developing children of this age, phonological processing skills are complete by this point so the measures may lack some sensitivity. Also, as phonological awareness is now widely recognized as providing the foundation for literacy acquisition in the field of UK education, it is likely that these children will have received specific interventions targeting phonological skills that may have remediated any deficits in this area.

Why is working memory skill such an effective and specific predictor of the severity of impairments in reading and mathematics in this sample? Swanson has argued that working memory provides a resource that allows the learner to integrate information retrieved from long-term memory with current inputs, and so that poor working memory capacities will compromise the child's attempts to carry out such important cognitive activities (Swanson \& Saez, 2003; Swanson \& Beebe-Frankenberger, 2004). A related view that we favor is that impairments of working memory result in pervasive learning difficulties because this system acts as a bottleneck for learning in many of the individual learning episodes required to 
increment the acquisition of knowledge (Gathercole, 2004). An observational study of study of children aged 5 and 6 years who performed very poorly on measures of verbal working memory provides support for this view (Gathercole, Lamont, \& Alloway, 2005). The children were working in the lowest ability groups in both literacy and mathematics within their classrooms, and were observed to make frequent errors in activities that placed heavy demands on working memory. Particularly high rates of failure were found in following complex instructions (which the child often forgot), performing tasks that imposed significant storage and processing loads, and in tasks with a complex hierarchical structure (in which the child often lost their place, and eventually abandoned prior to completion). Failures in these kinds of activities occurred frequently in both literacy and numeracy classes. On this basis, we have suggested that children with low working memory skills will have difficulties in meeting the routine working memory demands of many structured learning activities that are common in the classroom. This will lead to frequent task failures, which represent missed opportunities to learn and so to achieve normal incremental progress in complex skill domains.

This account of why impairments of working memory result in learning difficulties in both literacy and mathematics has important implications for provision of effective learning support for such children. It predicts that promoting teacher awareness of working memory loads in classroom activities and effective management of these loads for children with impairments of working memory should boost their learning. Current cognitive theory can be used to identify a number of methods for reducing working memory loads that could readily be applied to classroom practice (Gathercole \& Alloway, 2004). For example, task instructions should be short and syntactically simple, and repeated as required. In activities such as holding a sentence in mind while writing it down, the heavy storage and processing can be reduced by keeping sentences short and redundant, and using highly familiar 
vocabulary. External memory aids such as useful spellings and number lines should be provided for the child's use where possible, and the child encouraged to practice them under conditions of low working memory load. Tasks with complex structures could be simplified into component parts as a means of reducing the burden of monitoring the child's current place within the task. In addition, children may benefit from receiving training in self-help strategies for situations in which working memory fails.

In conclusion, the severity of deficits in the areas of both reading and mathematics in a sample of children with reading disabilities was closely associated with working memory skill. We propose that this association arizes because working memory acts as a bottleneck for learning in classroom activities, and suggest that effective management of working memory loads in structured learning activities may ameliorate the problems of learning that are associated with impairments of working memory. 


\section{References}

Alloway, T.P., Gathercole, S.E., \& Pickering, S. J. (2005). Short-term and working memory in children aged 4 to 11 years. Manuscript in preparation.

Alloway, T.P., Gathercole, S.E., Willis, C., \& Adams, A.M. (2004). A structural analysis of working memory and related cognitive skills in young children. Journal of Experimental Child Psychology, 87, 85-106.

Archibald, L.M.D., \& Gathercole, S.E. (2004). Short-term and working memory in Specific Language Impairment. Revised manuscript under review.

Baddeley, A.D. (1986). Working memory. Oxford: Oxford University Press.

Baddeley, A.D. (1996). Exploring the central executive. Quarterly Journal of Experimental Psychology, 49A, 5- 28.

Baddeley, A.D. (2000). The episodic buffer: A new component of working memory? Trends in Cognitive Sciences, 4, 417-423.

Baddeley, A.D., \& Hitch, G. (1974). Working memory. In G. Bower (Ed.), The Psychology of Learning and Motivation (pp. 47-90). New York: Academic Press.

Baddeley, A.D., \& Logie, R. H. (1999). The multiple-component model. In A. Miyake \& P. Shah (Eds.), Models of working memory: Mechanisms of active maintenance and executive control (pp. 28-61). New York: Cambridge University Press.

Bayliss, D.M., Jarrold, C., Gunn, MD., \& Baddeley, A.D. (2003). The complexities of complex span: Explaining individual differences in working memory in children and adults. Journal of Experimental Psychology: General, 132, 71-92.

Bowey, J.A. (1996). On the association between phonological memory and receptive vocabulary in five-year-olds. Journal of Experimental Child Psychology, 63, 44-78.

Bradley, L., \& Bryant, P.E. (1985). Rhyme and reason in reading and spelling. I.A.R.L.D. Monographs No.1. Ann Arbor: University of Michigan Press. 
Brady, S.A., \& Shankweiler, D.P. (Eds.). (1991). Phonological processes in literacy: A tribute to Isabelle Y. Liberman. Hillsdale, NJ: Erlbaum.

Cain, K., Oakhill, J., \& Bryant, P. (2004). Children's reading comprehension ability: concurrent prediction by working memory, verbal ability and component skills. Journal of Educational Psychology, 96, 31-42.

Case, R., Kurland, D. M., \& Goldberg, J. (1982). Operational efficiency and the growth of shortterm memory span. Journal of Experimental Child Psychology, 33, 386-404.

Catts, H., Gillispie, M., Leonard, L., Kail, R., \& Miller, C. (2002). The role of speed of processing, rapid naming, and phonological awareness in reading achievement. Journal of Learning Disabilities, 35, 509-524.

Cocchini, G., Logie, R.H., Della Sala, S., MacPherson, S.E., \& Baddeley, A.D. (2002). Concurrent performance of two memory tasks: Evidence for domain-specific working memory systems. Memory \& Cognition, 30, 1086-1095.

Conway, A. R. A., Kane, M. J., \& Engle, R. W. (2003). Working memory capacity and its relation to general intelligence. Trends in Cognitive Sciences, 7, 547-552.

Cowan, N. (2001). The magical number 4 in short-term memory: A reconsideration of mental storage capacity. Behavioral and Brain Sciences, 24, 87.

Daneman, M., \& Carpenter, P. A. (1980). Individual differences in working memory and reading. Journal of Verbal Learning and Verbal Behavior, 19, 450-466.

Della Sala, S., Gray, S., Baddeley, A.D., \& Wilson, L. (1997). Visual Patterns Test. London: Thames Valley Test Publishing.

Engle, R.W., Kane, M.J., \& Tuholski, S.W. (1999). Individual differences in working memory capacity and what they tell us about controlled attention, general fluid intelligence, and functions of the prefrontal cortex. In A. Miyake \& P. Shah (Eds.), Models of working 
memory: Mechanisms of active maintenance and executive control, pp. 102-134. New York: Cambridge University Press.

Engle, R. W., Tuholski, S. W., Laughlin, J. E., \& Conway, A. R. A. (1999). Working memory, short-term memory and general fluid intelligence: A latent variable approach. Journal of Experimental Psychology: General, 128, 309-331.

Frederickson, N., Frith, U., \& Reason, R. (1997). Phonological Assessment Battery. Windsor, UK: NFER Nelson.

Fry, A. F., \& Hale, S. (2000). Relationships among processing speed, working memory, and fluid intelligence in children. Biological Psychology, 54, 1-34.

Gathercole, S. E. (1999). Cognitive approaches to the development of short-term memory. Trends in Cognitive Science, 3, 410-418.

Gathercole, S. E. (2004). Working memory and learning during the school years. Proceedings of the British Academy, 125, 365-380.

Gathercole, S.E, \& Alloway, T.P. (2004). Working memory and classroom learning. Dyslexia Review, 15, 4-9.

Gathercole, S. E., Lamont, E., \& Alloway, T.P. (2005). Working memory in the classroom. In S.Pickering (Ed.). Working memory and education. Elsevier Press.

Gathercole, S. E. \& Pickering, S. J. (2000). Assessment of working memory in six- and sevenyear old children. Journal of Educational Psychology, 92, 377-390.

Gathercole, S. E., Pickering, S. J., Ambridge, B., \& Wearing, H. (2004). The structure of working memory from 4 to 15 years of age. Developmental Psychology, 40, 177-190.

Gathercole, S.E., Pickering, S.J., Knight, C., \& Stegmann, Z. (2004). Working memory skills and educational attainment: Evidence from National Curriculum assessments at 7 and 14 years of age. Applied Cognitive Psychology, 18, 1-16. 
Gathercole, S.E., Tiffany, C., Briscoe, J., Thorn, A.S.C. \& the ALSPAC Team (2005).

Developmental consequences of phonological loop deficits during early childhood: A longitudinal study. Journal of Child Psychology and Psychiatry. 46, 598-611.

Geary, D.C. (2004). Mathematics and learning disabilities. Journal of Learning Disabilities, 37, 4-15.

Geary, D.C., Hoard, M.K., Byrd-Craven, J., \& DeSoto, M.C. (2004). Strategy choices in simple and complex addition: Contributions of working memory and counting knowledge for children with mathematical disability. Journal of Experimental Child Psychology, 88, 121151.

Geary, D.C., Hoard, M.K., \& Hamson, C.O. (1999). Numerical and arithmetical cognition: Patterns of functions and deficits in children at risk for a mathematical disability. Journal of Experimental Child Psychology, 74, 213-239.

Jarvis, H. L., \& Gathercole, S. E. (in press). Executive functions and achievements on national curriculum tests: Shifting, updating, inhibition, and working memory. Quarterly Journal of Experimental Psychology.

Jarvis, H.L., \& Gathercole, S.E. (2003). Verbal and non-verbal working memory and achievements on national curriculum tests at 11 and 14 years of age. Educational and Child Psychology, 20, 123-140.

Just, M.A., \& Carpenter, P.A. (1992). A capacity theory of comprehension: Individual differences in working memory. Psychological Review, 99, 122-149.

Kane, M.J., Hambrick, D.Z., Tuholski, S.W., Wilhelm, O., Payne, T.W., \& Engle, R.W. (2004). The generality of working memory capacity: A latent variable approach to verbal and visuospatial memory span and reasoning. Journal of Experimental Psychology: General, 133, 189-217. 
Lobley, K., Gathercole, S. E., \& Baddeley, A. D. (in press). Is there a role for the phonological loop in verbal complex span?. Quarterly Journal of Experimental Psychology.

Metsala, J.L. (1999). The development of phonemic awareness in reading disabled children. Applied Psycholinguistics, 20, 149-158.

Miyake, A., Friedman, N.P., Emerson, M.J., Witzki, A.H., Howerter, A., \& Wager, T.D. (2000). The unity and diversity of executive functions and their contributions to complex 'frontal lobe’ tasks: A latent variable analysis. Cognitive Psychology, 41, 49-100.

Nation, K., Adams, J.W., Bowyer-Crane, C.A., \& Snowling, M.J. (1999). Journal of Experimental Child Psychology, 73, 139-158.

Vallar, G. \& Papagno, C. (2002). Neuropsychological impairments of verbal short-term memory. In A. D. Baddeley, M. D. Kopelman, \& B. A. Wilson (Eds.), Handbook of memory disorders (2nd edn), pp 249-270. Wiley.

Pickering, S.J., \& Gathercole, S.E. (2001). Working Memory Test Battery for Children. Psychological Corporation Europe.

Pickering, S.J., \& Gathercole, S.E. (2004). Distinctive working memory profiles in children with special educational needs. Educational Psychology, 24, 393-408.

Raven, J. (1986). Coloured Progressive Matrices. Oxford: Oxford Psycholinguistic Press. Rourke, B.P., \& Conway, J.A. (1997). Disabilities of arithmetic and mathematical reasoning: Perspectives from neurology and neuropsychology, Journal of Learning Disabilities, 30, 3446.

Shah, P., \& Miyake, A. (1996). The separability of working memory resources for spatial thinking and language processing: An individual differences approach. Journal of Experimental Psychology: General, 125, 4- 27.

Siegel, L.S. (1988). Evidence that IQ scores are irrelevant to the definition and analysis of reading-disability. Canadian Journal of Psychology, 42, 201-215. 
Siegel, L.S., \& Ryan, E.B. (1989). The development of working memory in normally achieving and subtypes of learning disabled children. Child Development, 60, 973-980.

Stanovich, K.E., \& Siegel, L.S. (1994). Phenotypic performance profile of children with reading disabilities: A regression-based test of the phonological-core variable-difference model. Journal of Educational Psychology, 86, 24-53.

Stothard, S. E., \& Hulme, C. (1992). Reading comprehension difficulties in children. Reading and Writing: An Interdisciplinary Journal, 4, 245-256.

Swanson, H.L. (1994). Short-term memory and working memory - Do both contribute to our understanding of academic achievement in children and adults with learning disabilities? Journal of Learning Disabilities, 27, 34-50.

Swanson, H.L. (1999). What develops in working memory? A life span perspective. Developmental Psychology, 35, 986-100.

Swanson, H.L. (2003). Age-related differences in learning disabled and skilled readers' working memory. Journal of Experimental Child Psychology, 85, 1-31.

Swanson, H. L., Ashbaker, M. H., \& Lee, C. (1996). Learning disabled readers working memory as a function of processing demands. Journal of Experimental Child Psychology, 61, 242275.

Swanson, H.L. \& Beebe-Frankenberger, M. (2004). The relationship between working memory and mathematical problem solving in children at risk and not at risk for math disabilities. Journal of Education Psychology, 96, 471-491.

Swanson, H.L., \& Howell, M. (2001). Working memory, short-term memory, and speech rate as predictors of children's reading performance at different ages. Journal of Educational Psychology, 93, 720-734. 
Swanson, H.L., \& Sachse-Lee, C. (2001). Mathematical problem solving and working memory in children with learning disabilities: Both executive and phonological processes ar e important. Journal of Experimental Child Psychology, 79, 294-321.

Swanson, H.L. \& Saez, L. (2003). Memory difficulties in children and adults with learning disabilities. In H.L. Swanson, S. Graham, \& K.R. Harris (Eds.), Handbook of learning disabilities, pp. 182-198. New York: Guildford Press.

Wagner, R. K, \& Muse. A. (in press). Working memory deficits in developmental dyslexia. In T. P. Alloway, T. P. \& S. E. Gathercole (Eds), Working memory in neurodevelopmental conditions. Psychology Press.

Wagner, R.K., \& Torgesen, J. (1987). The nature of phonological processing and its causal role in the acquisition of reading skills. Psychological Bulletin, 101, 192-212.

Wagner, R. K., et al. (1997). Changing relations between phonological processing abilities and word-level reading as children develop from beginning to skilled readers: A 5-year longitudinal study. Developmental Psychology, 33, 468-479.

Wechsler, D. (1992). Wechsler Intelligence Scale for Children - Third Edition UK. London: The Psychological Corporation.

Wechsler, D. (1993). Wechsler Objective Reading Dimensions. London: The Psychological Corporation.

Wechsler, D. (1996a). Wechsler Objective Numerical Dimensions. London: The Psychological Corporation.

Wechsler, D. (1996b). Wechsler Objective Language Dimensions. London: The Psychological Corporation.

Wilson, K. M., \& Swanson, H. L. (2001). Are mathematical disabilities due to a domain-general or a domain-specific working memory deficit? Journal of Learning Disabilities, 34, 237-248. 
Wolf, M., \& Bowers, P.G. (1999). The double-deficit hypothesis for the developmental dyslexias. Journal of Educational Psychology, 91, 415-438. 


\section{Author Note}

This research was supported by Medical Research Council co-operative group grant G0000257. 
Table 1

Descriptive statistics for literacy and mathematics measures (standard scores)

\begin{tabular}{lcccc}
\hline Measure & $M$ & $S D$ & Min. & Max. \\
\hline Reading & 78.91 & 6.51 & 63 & 90 \\
Reading & 82.07 & 7.51 & 64 & 93 \\
Spelling & 80.83 & 9.98 & 58 & 99 \\
Reading comp. & 76.46 & 8.44 & 55 & 85 \\
Composite score & & & & \\
Mathematics: & & & & \\
Mathematical reasoning & 89.59 & 10.27 & 62 & 111 \\
Number operations & 84.02 & 12.43 & 60 & 111 \\
Composite score & 84.39 & 12.13 & 58 & 108 \\
\hline
\end{tabular}


Table 2

Descriptive statistics for the principal measures; standard scores except where stated otherwise

\begin{tabular}{|c|c|c|c|c|c|}
\hline Measure & $M$ & $S D$ & Measure & $M$ & $S D$ \\
\hline Phonological STM: & & & Language: & & \\
\hline Digit recall & 90.35 & 16.48 & Oral expression & 93.30 & 8.10 \\
\hline Word recall & 89.09 & 11.32 & Language comp. & 88.91 & 10.65 \\
\hline Word list matching & 91.11 & 17.11 & Composite score & 87.78 & 10.69 \\
\hline Mean score & 90.18 & 11.08 & Verbal IQ: & & \\
\hline Complex memory: & & & Information $^{1}$ & 7.54 & 2.15 \\
\hline Backwards digit recall & 79.48 & 10.18 & Similarity $^{1}$ & 8.04 & 3.08 \\
\hline Counting recall & 73.72 & 13.84 & Mathematics ${ }^{1}$ & 6.28 & 2.67 \\
\hline Listening recall & 79.98 & 13.53 & Vocabulary $^{1}$ & 7.37 & 2.40 \\
\hline Mean score & 77.72 & 8.96 & Comprehension $^{1}$ & 7.26 & 3.32 \\
\hline Visuo-spatial STM: & & & IQ score & 83.39 & 11.86 \\
\hline Block recall & 71.65 & 13.73 & Performance IQ: & & \\
\hline Visual patterns & 78.61 & 10.73 & Picture completion $^{1}$ & 8.24 & 3.63 \\
\hline Mean score & 75.13 & 9.56 & Coding $^{1}$ & 7.13 & 3.02 \\
\hline Phonological processing: & & & Picture arrangement ${ }^{1}$ & 7.74 & 2.69 \\
\hline Rhyme & 87.26 & 11.75 & Block design $^{1}$ & 6.45 & 3.10 \\
\hline Spoonerisms & 92.85 & 10.57 & Object assembly $^{1}$ & 7.78 & 3.33 \\
\hline Alliteration & 82.83 & 14.85 & IQ score & 82.35 & 13.84 \\
\hline Mean score & 88.78 & 8.40 & & & \\
\hline
\end{tabular}

${ }^{1}$ Scaled score $(M=10, S D=3)$ 
Table 3

Proportions of children obtaining bands of standard scores for each measure

\section{Measure}

Complex Phonological Visuospatial Phonological Language Verbal IQ Performance

\begin{tabular}{lccccccc} 
Band & memory & STM & STM & processing & & & IQ \\
\hline$<81$ & 0.61 & 0.22 & 0.70 & 0.22 & 0.33 & 0.39 & 0.52 \\
$81-85$ & 0.78 & 0.35 & 0.87 & 0.33 & 0.46 & 0.57 & 0.65 \\
$86-90$ & 0.91 & 0.48 & 0.96 & 0.50 & 0.59 & 0.72 & 0.72 \\
$91-95$ & 0.98 & 0.70 & 1.00 & 0.80 & 0.78 & 0.85 & 0.85 \\
$96+$ & 1.00 & 1.00 & 1.00 & 1.00 & 1.00 & 1.00 & 1.00 \\
\hline
\end{tabular}


Table 4

Intercorrelations between cognitive skills and achievement measures

\begin{tabular}{|c|c|c|c|c|c|c|c|c|c|}
\hline \multicolumn{2}{|c|}{ Measures } & 1 & 2 & 3 & 4 & 5 & 6 & 7 & 8 \\
\hline 1 & Phonological STM & - & & & & & & & \\
\hline 2 & Complex memory & $320 *$ & - & & & & & & \\
\hline 3 & Visuo-spatial STM & 174 & $443 *$ & - & & & & & \\
\hline 4 & Phonological processing & 244 & $582 *$ & $243^{*}$ & - & & & & \\
\hline 5 & Language & 049 & $324 *$ & 213 & 179 & - & & & \\
\hline 6 & Verbal IQ & 052 & $393 *$ & 141 & $336 *$ & $679 *$ & - & & \\
\hline 7 & Performance IQ & 126 & $546 *$ & $411^{*}$ & $415^{*}$ & $365 *$ & $556^{*}$ & - & \\
\hline 8 & Reading & 167 & $557 *$ & 162 & $442 *$ & $478 *$ & $350 *$ & $330 *$ & - \\
\hline 9 & Mathematics & $338 *$ & $591 *$ & 254 & $496 *$ & $414^{*}$ & $537 *$ & $427^{*}$ & $582 *$ \\
\hline
\end{tabular}


Table 5

Hierarchical regression analysis for the criterion measure of reading scores

\begin{tabular}{llllc}
\hline & \multicolumn{5}{c}{ Reading } \\
\hline Independent variable & $\mathrm{B}$ & $\mathrm{SE}$ & $\mathrm{b}$ & $\mathrm{t}$ \\
\hline Model 1: & & & & \\
Verbal IQ & -0.092 & 0.130 & -0.130 & -0.713 \\
Performance IQ & -0.026 & 0.096 & -0.043 & -0.273 \\
Language & 0.334 & 0.129 & 0.423 & $2.595^{*}$ \\
Phonological processing & 0.213 & 0.149 & 0.212 & 1.430 \\
Complex memory & 0.349 & 0.152 & 0.371 & $2.295^{*}$ \\
$R^{2}=.443, \mathrm{~F}(5,40)=6.375, p<.001$ & & & & \\
Model 2: & & & & \\
Mathematics & 0.230 & 0.110 & 0.330 & $2.098^{*}$ \\
Verbal IQ & -0.165 & 0.129 & -0.232 & -1.279 \\
Performance IQ & -0.017 & 0.093 & -0.028 & -0.185 \\
Language & 0.316 & 0.124 & 0.401 & $2.533^{*}$ \\
Phonological processing & 0.151 & 0.146 & 0.151 & 1.034 \\
Complex memory & 0.236 & 0.156 & 0.251 & 1.518 \\
$R^{2}=.499, \mathrm{~F}(6,39)=6.481, p<.001$ & & & & \\
\hline$* p<.05$ & & & & \\
\hline
\end{tabular}


Table 6

Hierarchical regression analysis for the criterion measure of mathematics scores

\begin{tabular}{|c|c|c|c|c|c|c|c|c|c|}
\hline Independent variable & $\mathrm{B}$ & $\mathrm{SE}$ & $\mathrm{b}$ & $\mathrm{t}$ & Independent variable & $\mathrm{B}$ & $\mathrm{SE}$ & $\mathrm{b}$ & $\mathrm{t}$ \\
\hline Model 1: & & & & & Model 3: & & & & \\
\hline Verbal IQ & 0.332 & 0.177 & 0.325 & 1.880 & Verbal IQ & 0.325 & 0.183 & 0.318 & 1.777 \\
\hline Performance IQ & -0.033 & 0.131 & -0.038 & -0.251 & Performance IQ & 0.053 & 0.128 & 0.061 & 0.418 \\
\hline Language & 0.078 & 0.175 & 0.069 & 0.445 & Language & 0.128 & 0.179 & 0.113 & 0.715 \\
\hline Phonological processing & 0.242 & 0.204 & 0.168 & 1.185 & Phonological processing & 0.412 & 0.190 & 0.285 & $2.164 *$ \\
\hline Complex memory & 0.412 & 0.213 & 0.305 & 1.933 & Phonological STM & 0.261 & 0.131 & 0.239 & 1.999 \\
\hline Phonological STM & 0.202 & 0.130 & 0.184 & 1.549 & \multicolumn{5}{|c|}{$R^{2}=.465, \mathrm{~F}(5,40)=6.965, p<.001$} \\
\hline \multicolumn{10}{|l|}{$R^{2}=.512, \mathrm{~F}(6,39)=6.824, p<.001$} \\
\hline Model 2: & & & & & \multicolumn{5}{|l|}{ Model 4: } \\
\hline Verbal IQ & 0.317 & 0.18 & 0.310 & 1.765 & Verbal IQ & 0.365 & 0.176 & 0.357 & $2.079 *$ \\
\hline Performance IQ & -0.040 & 0.133 & -0.046 & -0.301 & Performance IQ & -0.020 & 0.131 & -0.022 & -0.882 \\
\hline Language & 0.078 & 0.178 & 0.069 & 0.437 & Language & 0.051 & 0.175 & 0.045 & 0.292 \\
\hline Phonological processing & 0.270 & 0.207 & 0.187 & 1.308 & Complex memory & 0.521 & 0.193 & 0.385 & $2.694 *$ \\
\hline Complex memory & 0.491 & 0.211 & 0.362 & $2.328 *$ & Phonological STM & 0.216 & 0.13 & 0.197 & 1.654 \\
\hline$R^{2}=.482, \mathrm{~F}(5,40)=7.499, p<.001$ & & \multicolumn{8}{|c|}{$R^{2}=.495, F(5,40)=7.829, p<.001$} \\
\hline
\end{tabular}

$* p<.05$ 